\title{
Terpenoids and Gibberellic Acids Interaction in Plants
}

\author{
Zahra Asrar \\ Department of Biology, Shahid Bahonar University of Kerman, Kerman
}

Iran

\section{Introduction}

Plants synthesize an astonishing diversity of isoprenoids, some of which play essential roles in photosynthesis, respiration, and the regulation of growth and development. In spite of economic significance of the terpenoids and their many essential functions, relatively little is known about terpenoid metabolism and its regulation in plants (Mansouri et al, 2009). However, two independent patheways for the biosynthesis of isoprenoid precursors coexist within the plant cell: the cytosolic mevalonic acid (MVA) pathway and the plastidial methyerythritol phosphate (MEP) pathway. Cannabis is a diecious species that is a source of fiber, food, oil and medicine. Cannabinoids represent a distinctive class of compounds belong to the chemical class of natural terpenophenols. Among others, $\Delta^{9}$-tetrahycannabinol (THC) and cannabidiol (CBD) are the most important of these compounds. The experiments with labeling patterns showed that the cannabinoids are derived entirely or predominantly (98\%) from the deoxyxylulose pathway (Fellemeier et al., 2001). They are produced by glandular trichomes that occur on most aerial surfaces of the plant (Hilling 2004). Cannabis is used in modern medicine for the treatment of emesis in chemotherapy. As well as being useful anti-emetics, cannabinoids appear to have therapeutic value as antispasmodics, analgesics, and appetite stimulants and have potential in the treatment of epilepsy, glaucoma, and asthma (Agurell and Nilsson 1972; Guzman 2003; Howlett et al., 2004).

However little is known about the effects of plant hormones on the regulation of these pathways. Thus, we investigated the effect of gibberellic acid $\left(\mathrm{GA}_{3}\right)$ on changes in the amount of many produced terpenoids and the activity of the key enzymes, 1-deoxy-D-xylulose 5phosphate synthase (DXS) and 3-hydroxy-3-methy glutaryl coenzyme A reductase (HMGR) in these pathways. To understand the role of gibberellic acid $\left(\mathrm{GA}_{3}\right)$ in the regulation of two terpenoid biosynthesis pathways, we gained experience on the response of the main end products of these pathways and cannabinoids under $\mathrm{GA}_{3}$ treatment in cannabis plants.

This chapter will provide focus on recent development of the interaction effects of terpenoids and gibberellic acid in Cannabis sativa.

\section{Biosynthesis of terpenoids}

Isoprenoids (also known as terpenoides) made from assembly of isoprene units. Isoprenes are flexible five carbon units $-\left(\mathrm{CH}_{2}\right)_{2} \mathrm{C}=\mathrm{CH}-\mathrm{CH}_{2^{-}}$, and they comprise a diverse class of plant 
metabolites; most of them are known as defense-related compounds, flavors or scents (Chris et al., 2007). Terpenoids constitute the largest family of natural plant products, with over 30,000 members (Dewick, 2002). Members of this diverse group of natural products are found in all organisms. In primary metabolism, they function as photosynthetic pigments (chlorophylls and carotenoids), electron transport (ubiquinone and plastoquinone), plant hormones (abscisic acid and gibberellins) and membrane fluidity such as sterols (Lang and Ghassemian, 2003; Mcgarvey and Croteau, 1995). The plant produced isoprenoids $\beta$-carotene (provitamine A) and a-tocopherol (VitE) are required for the maintenance of human health (Shintani and Dellapenna, 1998; Hirschberg, 1999). Industrial uses of isoprenoids include products such as colorants, fragrance, and flavorings (Lang and Croteau, 1999).

Otto Wallach who in 1910 recognized that isoprene is the basic constituent of terpens (Fig. 1) and Leopold Ruzicha found that isoprene is the basic element for the synthesis of many natural compounds including steroids. He postulated the biogenic isoprene rule, according to which all terpenoids (derivatives of terpens) are synthesized via a hypothetical precursor which he named active isoprene. This speculation was verified by Feodor Lynen in 1964, when he identified isopentenyl pyrophosphate to be "the active isoprene" (Heldt, 2005).

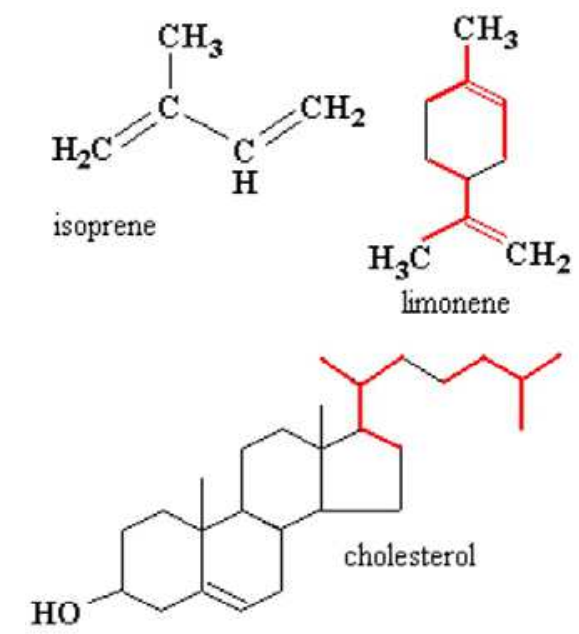

Fig. 1. Isoprene unit and Terpens

\subsection{Terpenoids have two different biosynthetic pathways}

All isoprenoides are derived from the ubiquitous C5 building blocks isopentenyl diphosphate (isopentenyl pyrophosphate) (IPP) and dimethylallyl diphosphate (DMAPP). These precursors can be synthesized by independent pathways in higher plants and algae (Lichtenthaler, 1999), the classical mevalonate pathway in the cytoplasm or the alternative non-mevalonate pathway in plastids (Arigoni et al., 1997; Rohmer, 1999). The plastidial pathway, now known as the 2-C-methy-D-erythriol-4-phosphate (MEP) pathway, has been fully elucidated by a combination of biochemical and genomic approaches (Rodriguez and Boronat, 2002); it provides the precursors for monoterpenes, diterpenes, carotenoids, tocopherols, and the prenyl moiety to chlorophyll (Eisenreich et al., 2001). 


\subsubsection{Mevalonate pathway}

Konrad Bloch in 1964 discovered that acetyl CoA is a precursor for the biosynthesis of steroids. In fact, the mevalonate pathway (MVA pathway) has long been assumed to be the exclusive biosynthesis route used in all organisms for the synthesis of Isopentenyl pyrophosphate (IPP); particularly in mammalian where it is responsible for the biosynthesis of cholesterols. Fig. 2 shows the synthesis of the intermediary product IPP: two molecules of acetyl $\mathrm{CoA}$ react to produce acetoacety $\mathrm{CoA}$ and with another acety $\mathrm{CoA}$ yielding $\beta$ hydroxy- $\beta$ methyl glutaryl CoA (HMG CoA). In plants a single enzyme, HMG CoA synthase catalyzes both reactions (Heldt, 2005). Several studies have emphasized the regulatory role of 3-hydroxy 3-methy glutaryl CoA enzyme reductase (HMGR) in the mevalonate pathway. HMG $\mathrm{R}$ is considered to be the most heavily regulated enzyme in mammalian metabolism (Goldstein and Brown, 1990) and there are numerous studies demonstrating that it is also closely regulated in plants, particularly in the case of sterol and phytoalexine synthesis (Weissenborn, 1995; Stermer et al., 1994).

The esterified carboxyl group of HMG Co A is reduced by two molecules of NADPH to a hydroxyl group accompanied by hydrolysis of the energy-rich thioester bond. Thus mevalonic acid is formed. A pyrophosphate ester is formed in two successive phosphorylation steps, catalyzed by two different kinases. Third molecule of ATP, then involving the transitory formation of a phosphate ester, a carbon-carbon double bond is generated and the remaining carboxyl group is removed (Heldt, 2005). Isopentenyl pyrophosphate is the basic unit for the formation of an isoprenoid chain and the cytosolic pathway, which starts from acetyl-CoA and proceeds through the intermediate mevalonate (MVA), provides the precursors for sterols and ubiquinons (Laule et al., 2003).

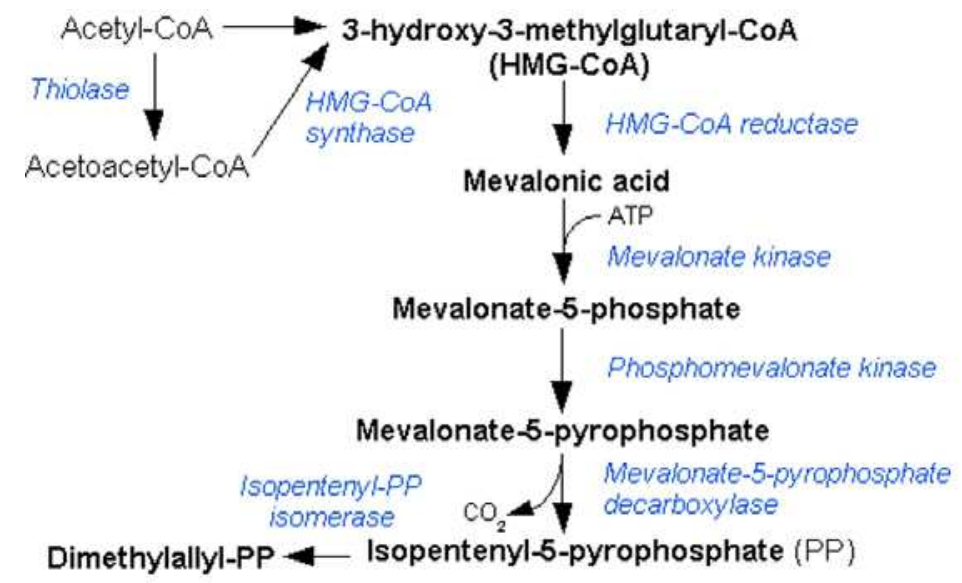

Fig. 2. Scheme of Mevalonate (MVA) pathway from acetyl CoA to Isopenteny phyrophosphate (IPP)

\subsubsection{The DOXP/ MEP pathway}

Experiments with plants led to the discovery that synthesize of isopentenyl pyrophosphate in the plastids follow a different pathway (Fig. 3). The precursors for this pathway are 


\section{DOXP/MEP Pathway}
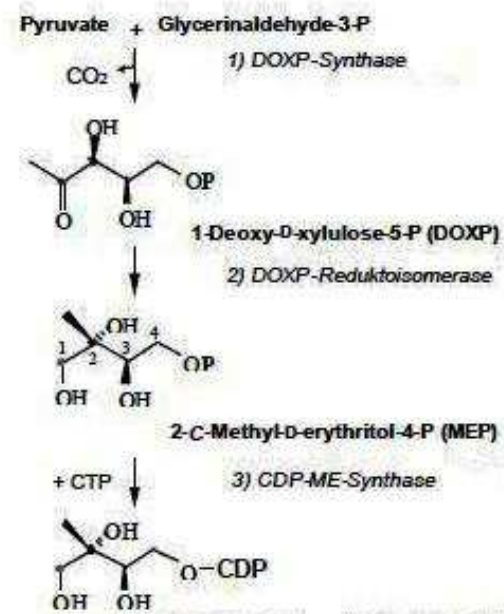

CDP-MethyL-D-erythritol (CDP-ME)

+ ATP
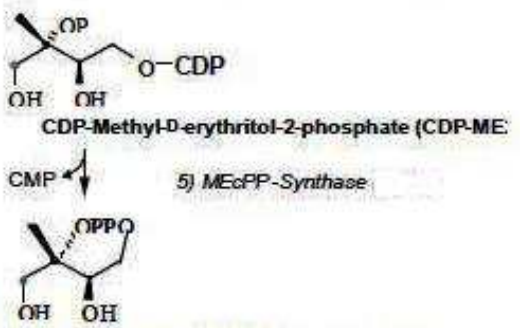

2-C-Methyl-D-erythritol 2,4-cyclo-diphosphate (MEcPP)

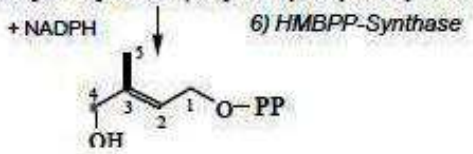

4-Hydroxy-3-methyl-2-(E)-butenyl-diphosphate (HMBPP)

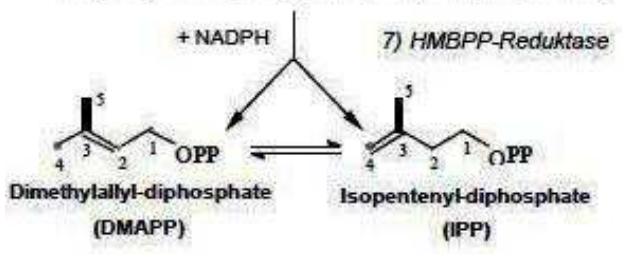

Fig. 3. Scheme of 1-deoxy-D-xylulose-5-phosphate/methyl-D-erythrithol (DOXP/MEP pathway). The enzymes of both pathways are numbered. MEP/DOXP pathway for isopentenyl diphosphate (IPP) and isoprenoid biosynthesis 
pyruvate and D-glyceraldehyde-3-phosphate. Pyruvate is decarboxylated via thiamine pyrophosphate (TPP) and then is transferred to D-glyceraldehyde-3-phosphate to yield 1deoxy-D-xylulose-5-phosphate (DOXP). After isomerization and reduction by NADPH, 2C-methyl erythriol-4-phosphate (MEP) is synthesized. MEP is then activated by reacting with CTP to yield CDP methyl erythriol. Two further reduction steps, following dehydration and phosphorylation. Finally yield isopentenyl pyrophosphate (Heldt, 2005).

The MEP-synthase pathway for isoprenids is present in bacteria, algae, and plants, but not in animals. A large part of plant isoprenoids, including the hemiterpene, monoterpenes like limnone, phytohormones such as gibberellins (Crozier et al., 2000), brasinoesteroids, and phytoalexine (Lang and Gassemian, 2003; Kanno et al., 2006).

The production and accumulation of cannabinoids in plants of Cannabis sativa follow nonmevalonate pathway (Fellermeier et al., 2001) synthesized via the MEP pathway located in plastids (Rohmer, 1999).

1-deoxy-D-xylulose-erythriol phosphate synthase (DXS) catalyzes the first step in the methy-erythriol phosphate (MEP) pathway and is hypothesized to be an important control step within MEP pathway (Lichtenthaler, 1999). The role of the DXS in plants can be seen in Arabidopsis, the over expression of DXS led to an increase in terpenoids concentrations while the repression of DXS decreased terpenoid concentrations (Estevez et al., 2001).

\section{Biosynthesis of gibberellins}

Farmers in Asia were aware of a disease of rice plants called bakanae (foolish seedling) disease. Infected plants would grow excessively taller than normal healthy plants, and being fall over and be unharvestable. This disease was found to be caused by a fungus known as Gibberella fujikuroi (Yabuta, T., 1935). Thus, Work on this special disease in Japan occurred by Japanese scientists who isolated a growth promoting substances from cultures of a fungus that parasitizes rice plants in the 1930s. They called it gibberellin. Scientists in the 1950s rediscovered this work and extracted a range of chemical that elicit the growth response in rice seedlings. Since that time, more than 100 slightly different gibberellins have been identified chemically.

Gibberellins (GAs) are diterpene plant hormones or plant growth regulator of vascular plants, fungi, and bacteria that are biosynthesized through complex pathways and control diverse aspects of growth and development, including seed germination, shoot elongation, leaf expansion, pollen-tube growth, trichome, flower and fruit development, cell division, cell elongation and floral transition (Olszewski et al., 2002; Razem et al., 2006). Among more than a hundered GAs identified from plants (http://www.plant-hormones.info/ gibberelline-nomenclature.htm), only a small number of them, such as $\mathrm{GA}_{1}, \mathrm{GA}_{3}, \mathrm{GA}_{4}$, and $\mathrm{GA}_{7}$ are thought to function as bioactive (biologically active gibberellins) hormones. Therefore, many non bioactive gibberellins exist in plants as precursors for the bioactive forms or deactivated metabolism (Yamaguchi, 2008). The major bioactive GAs, commonly have a hydroxyl group on C-3 $\beta$, a carboxyl group on C- 6 and a lactone between C- 4 and C10 (Fig. 4). GAs has been identified frequently in a variety of plant species, implying that it acts as a widespread bioactive hormone. 


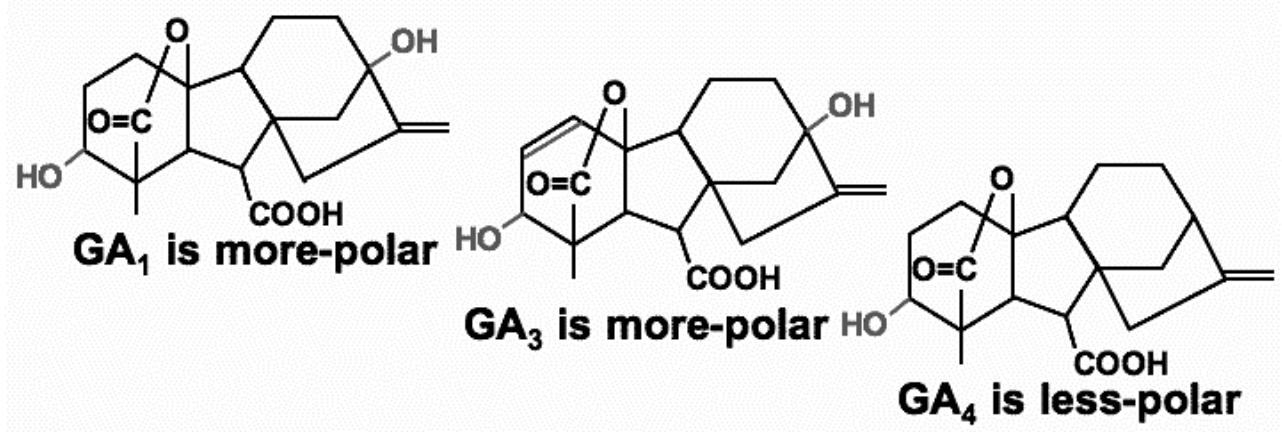

Fig. 4. Active Gibberellins

According to the nature of the enzymes involved, gibberellins biosynthesis pathways are usually divided into three parts. Each of the three parts consists of several steps:

\section{I- Biosynthesis of ent-Kaurene}

Recentely, a second, MVA- independent pathway to isopentenyl pyrophosphate (IPP) via glyceraldehydes 3-phosphate and pyruvate was discovered in a green alga (Schwender et al., 1996). Isopentenyl pyrophosphate is further converted to gerany geranyl pyrophosphate (GGPP) by two enzymes, IPP-isomerase and GGPP-synthase in plastids of higher plants (Dogbo \& Camara, 1987).

Gerany gerany pyrophosphate is cyclized to ent-copalyl pyrophosphate (CPP) and finally to ent-kaurene. In higher plants these reactions are catalyzed by two enzymes, CPP synthase formerly Kaurene synthase A and ent-Kaurene (K) synthase formerly Kaurene synthase B, renaming was suggested by Mcmillan 1979. Both enzymes were localized in isolated proplastids of meristematic shoot tissues, but not in mature chloroplasts of pea and wheat (Aachet al., 1995, 1997) or of pumpkins endosperm (Simcox et al., 1975; Aach et al., 1995).

\section{II- From ent-Kaurene to $\mathrm{GA}_{12}$}

In the second stage of GA biosynthesis (Fig. 5), the C-19 methy $\left(\mathrm{CH}_{3}\right)$ group of Kaurene is oxidized in three steps to give ent-kaurenoic acid (KA). These oxidations are catalyzed by ent-kaurene oxidase $(\mathrm{KO})$, which is multifunctional because it can catalyze all three reactions. In Arabidopsis, $\mathrm{KO}$ is encoded by $\mathrm{GA}_{3}$, and mutation in this gene will again produce severly dwarfed plant (Shinjiro, 2008).

The intermediate, second, part of the pathway is catalyzed by microsomal NADPHdependent cytochrome P-450 monooxygenases at the endoplasmic reticulum (Lange, 1998). Thus, the precursor ent-kaurene must be translocated from the proplastids to the endoplasmic reticulum, although nothing is known about the transport mechanism (Lange, 1998). Ent-kaurene is oxidized into $\mathrm{GA}_{12}$, via ent-kaurenol, ent kaurenal, entkaurenoic acid, ent-7a-hydroxy kaurenoic acid, and GA12-aldehyde. Certain biosynthesis steps, Such as 7oxidation, 12a-hydroxylation, and 13-hydroxylation are catalyzed by both monooxygenases and soluble dioxygenases, which occasionally occur together within the same species or even within the same tissue (Lange \& Graebe, 1993). 


\section{III- Gibberellins from GA12}

Some initial steps of the final part of pathway might overlap with the second part. However, the third part starts with GA12-aldehyde is oxidized by soluble 2-oxoglutarate- dependent dioxygenases (Fig. 5). The GA dioxygenases are multifunctional with broad substrate specificity, resulting in many side reactions and numerous gibberellines found in higher plants (Lange \& Graebe, 1993; Hedden \& Kamiya, 1997).

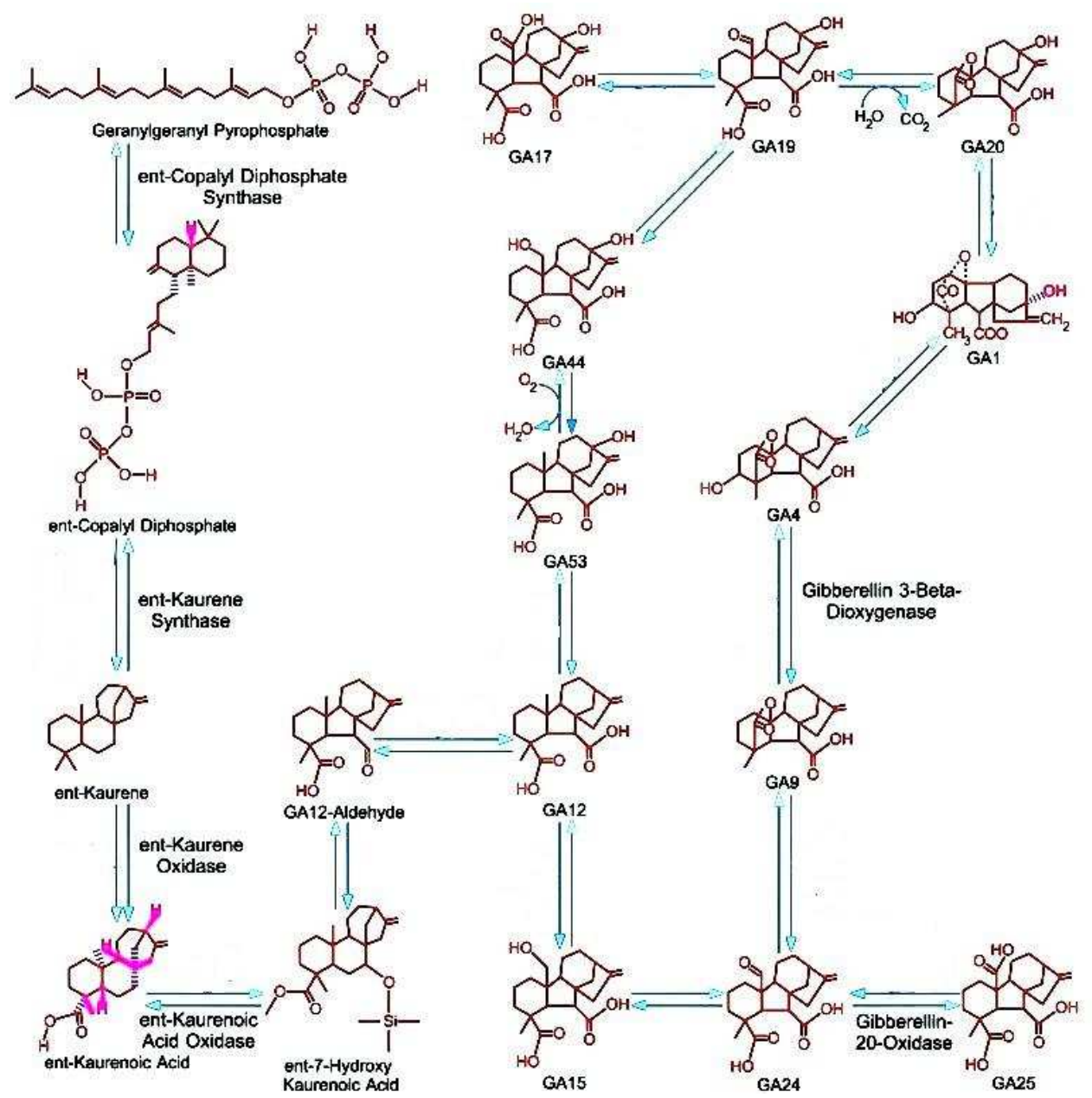

Fig. 5. Scheme of gibberellins biosynthesis (DXS) in the leaves of cannabis plants.

\section{The interaction effect of terpenoids and $\mathrm{GA}_{3}$ at vegetative stage}

The influence of gibberellic acid $\left(\mathrm{GA}_{3}\right)$ on plastidic and cytosolic terpenoids and on two key enzymes, 1-deoxy-D-xylulose-5-phosphate synthase (DXS) and 3-hydroxy-3-methylglutaryl coenzyme A reductase (HMGR), for terpenoid biosynthesis was compared in vegetative 
cannabis plants. However, the regulation of the biosynthesis of terpenoids in plant cell is poorly understood. We do not know how the metabolite fluxes between the primary and secondary metabolisms are orchestrated. Plant growth regulators have essential roles in growth and development of plants and plant resposes to environment. In order to understand how interact with terpenoid biosynthesis; we focused on the role of $\mathrm{GA}_{3}$ in the regulation of primary and secondary terpenoid production in Cannabis sativum at vegetative stage.

Treatment with exogenous $\mathrm{GA}_{3}$ resulted in a decrease of DXS activity in comparison with the control plants (Fig. 6). Although, there is no report on the effect of $\mathrm{GA}_{3}$ on DXS activity, many reports support a regulatory role of DXS for the production of MEP-derived isoprenoids in plants (Rodriguez-concepcion, 2006). Estevez et al (2001) reported that transgene mediated up regulation or down regulation of DXS levels in Arabidopsis were correlated with concomitant changes in the levels of MEP derived isoprenoid end product.

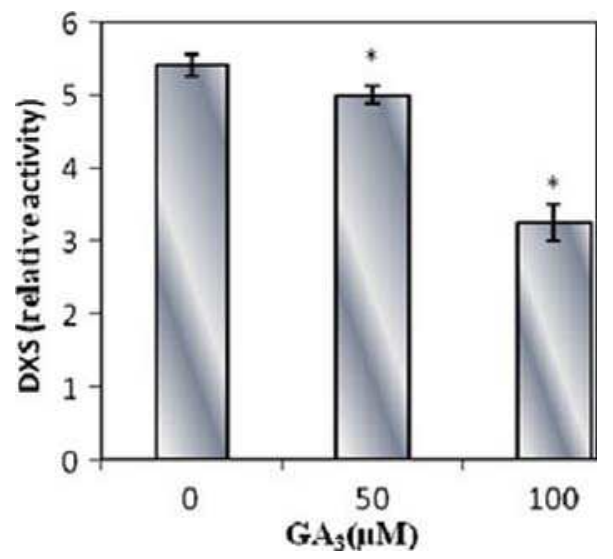

Fig. 6. Effects of gibberellic acid (GA3) on 1-deoxy-D-xylulose 5-phosphate synthase (DXS) in the leaves of cannabis plants.

The effects of the concentration of $\mathrm{GA}_{3}$ on the chlorophyll and carotenoid contents of cannabis leaf are present in Fig. $7 \& 8$. Reduction in chlorophyll content after $\mathrm{GA}_{3}$ application has been reported in wheat (Misra \& biswal, 1980), rice seedlings (Yim et al., 1997) and pea (Bora \& Sarma, 2006) which are consistence with our results (Mansouri et al., 2011).The variation in the level of the cartenoids were similar to those observed for the chlorophylls. Apparently carotenoids and chlorophylls accumulation are controlled through a similar mechanism, because both of them are reduced by $\mathrm{GA}_{3}$. The changes in chlorophyll and carotenoid were parallel with changes in DXS activity. It can show the limiting role of DXS activity in chlorophyll and carotenoid synthesis.

The tocopherol is lipophilic antioxidants that are synthesized by photosynthetic organisms, occurring mainly in leaves and seeds. Literature sources indicate that the major tocopherol form in leaf tissues is a - tocopherol (Szymanska and Kruk, 2008). Abdul Jaleel et al. (2007) reported that $\mathrm{GA}_{3}$ treatment stimulated $a-$ tocopherol accumulation in Catharanthus roseus. The $\mathrm{a}-$ tocopherolcontent of cannabis plants decrease in $50 \mu \mathrm{M} \mathrm{GA}$ treatment and increased with increasing $\mathrm{GA}_{3}$ at vegetative stage (Fig. 9) which is consistence with other reports. 


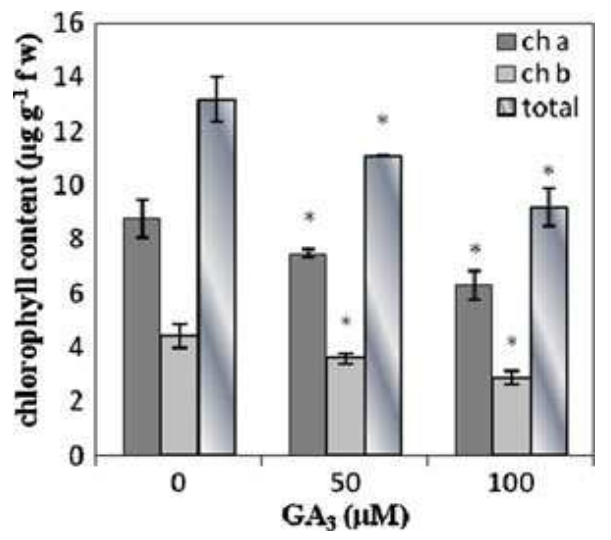

Fig. 7. Effects of gibberellic acid (GA3) on chlorophylls a, b and total in the leaves of cannabis plants.

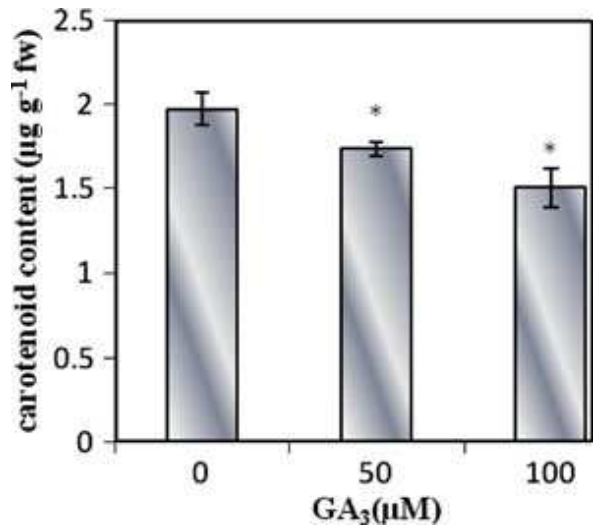

Fig. 8. Effects of gibberellic acid (GA3) on carotenoids in the leaves of cannabis plants.

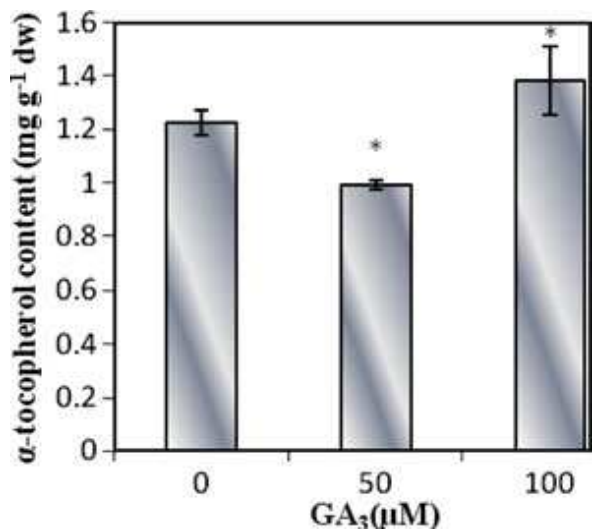

Fig. 9. Effects of gibberellic acid (GA3) on a-tocopherol content in the leaves of cannabis plants 


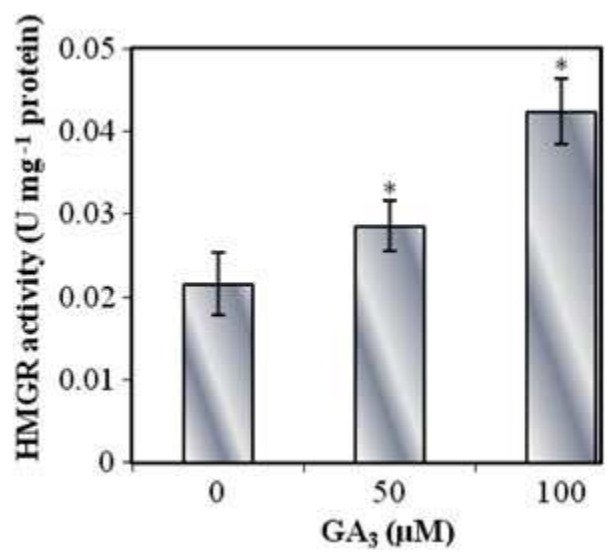

Fig. 10. Effects of gibberellic acid (GA3) on 3-hydroxy-3-methylglutaryl coenzyme A reductase (HMGR) activities in the leaves of cannabis plants.

Exogenous $\mathrm{GA}_{3}$ caused an increasing in HMGR activity (Fig. 10). Since HMGR is an important control point for the MVA pathway in plants (Kato-Emori et al., 2001), the increase in HMGR activity should result in increasing the supply of phytosterols. Squalene and phytosterol contents showed similar changes and increased concomitant with HMGR activity in cannabis plants (Fig.11, 12). Consistent with our results, pea seedlings treated with $\mathrm{GA}_{3}$ showed an increase in the HMGR activity (Russell \& Davidson, 1982).

The amount of THC and CBD increase with increasing $\mathrm{GA}_{3}$ treatment in comparison with the control plants (Fig. 13).The THC content was higher than those of CBD content (Mansouri et al., 2011). Perhaps, the increase observed in the THC and CBD content at high level of $\mathrm{GA}_{3}$ is not a direct effect of $\mathrm{GA}_{3}$ treatment and could reflect the $\mathrm{GA}_{3}$ interaction with other plant hormones. As has been shown that exogenous application of GA3 caused a clear increase in ACC content. ACC oxidase activity and ethylene biosynthesis occur during the breaking of dormancy and onset of germination in Fagus sylvatica L. seeds (Calvo et al., 2004). Furthermore, it is possible that ethylene caused the increase observed in THC and CBD content.

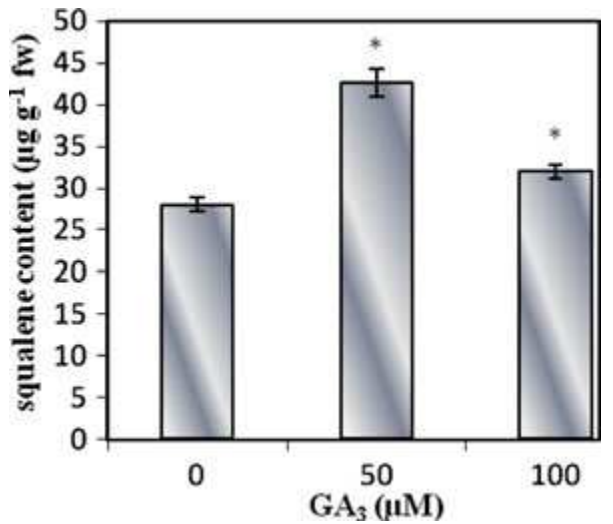

Fig. 11. Effects of gibberellic acid (GA3) on squalene content in the leaves of cannabis plants. 


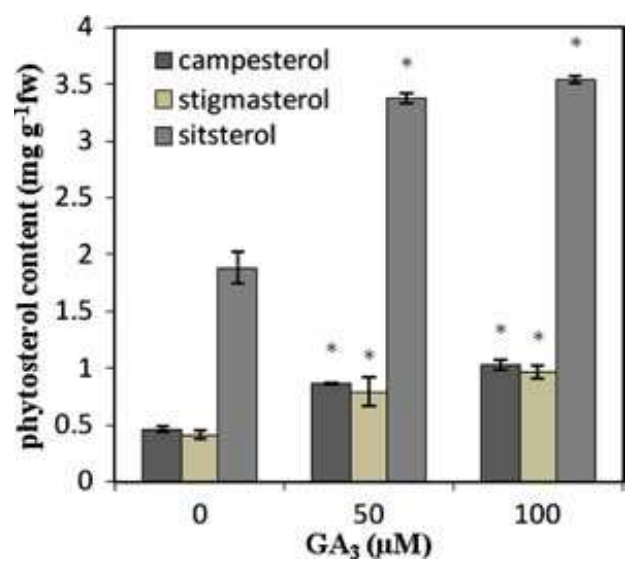

Fig. 12. Effects of gibberellic acid (GA3) on phytosterol content in the leaves of cannabis plants.

On the whole, these results showed that $\mathrm{GA}_{3}$ treatment had opposite effect on primary terpenoid biosynthesis by MVA and MEP pathways. $\mathrm{GA}_{3}$ treatment caused a decrease in DXS activity and biosynthesized primary terpenoids from MEP pathway, but this treatment increased HMGR activity and phytosterols from MVA pathway. Whereas, secondary terpenoids showed different response to $\mathrm{GA}_{3}$ treatment and it could be because of interference of two biosynthetic pathways in their formation.

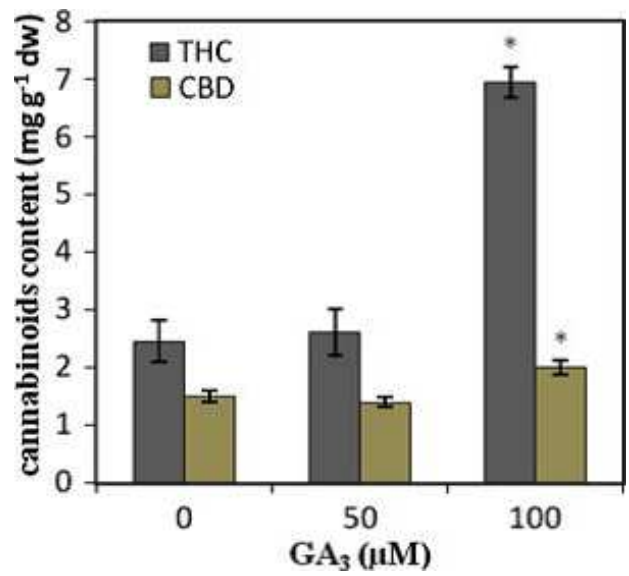

Fig. 13. Effects of gibberellic acid (GA3) on THC and CBD content in the leaves of cannabis plants.

\section{The effect of GA3 and terpenoids at flowering stage}

In spite of economic importance of the terpenoids and their many essential functions, relatively little is known about terpenoid metabolism and its regulation in plants. To understand the role of gibberellic acid $\left(\mathrm{GA}_{3}\right)$ in the regulation of two terpenoid biosynthesis 
pathways, we studied the response of the main end products of these pathways and cannabinoids under $\mathrm{GA}_{3}$ treatment in cannabis plants.

Effects of different concentrations of $\mathrm{GA}_{3}$ on levels of chlorophyll, carotenoids and atocopherol in leaves of male and female cannabis plants were investigated. Male plants treated with $50 u \mathrm{M} \mathrm{GA}_{3}$ had lower chlorophyll a and total contents compared to the control (Fig. 14A). Treatment of female leaves with 50 and $100 u \mathrm{M} \mathrm{GA} 3$ significantly decreased chlorophyll a, b and total contents in a dose-dependent pattern (Fig. 14B). The carotenoid contents of treated plants were lower compared with the control (Fig. 15A). Low concentrations of $\mathrm{GA}_{3}$ were more effective on decreasing carotenoid contents in male plants.

The phytyl $\left(\mathrm{C}_{20}\right)$ conjugates chlorophylls and tocopheroles, and carotenoids $\left(\mathrm{C}_{40}\right)$ are produced by the MEP pathway. $\mathrm{GA}_{3}$ treatment decreased chlorophyll contents in C.sativa plants. Reduction in chlorophyll content after $\mathrm{GA}_{3}$ application has been reported in, wheat (Misra \& Biswal 1980), peach trees (Monge et al. 1994), rice seedlings (Yim et al. 1997) and pea (Bora \& Sarma 2006). Perez et al. (1974) have shown that a mutant of tomato with increased levels of $\mathrm{GA}_{3}$ contains less chlorophyll. Our results showed that $\mathrm{GA}_{3}$ caused a decrease in carotenoid contents (Fig. 14). Apparently carotenoid and chlorophyll accumulationis controlled through a similar mechanism, because both of them are reduced by $\mathrm{GA}_{3}$. The previous studies indicate that $\mathrm{GA}_{3}$ treatments delayed the chloroplast chromoplast conversion of colored fruit (Goldshmidt, 1998; Pfander, 1992). The development of chromoplasts is accompanied by the accumulation of carotenoids (Vainstein et al., 1994). Also by Rodrigo and Zacarias (2007) reported that $\mathrm{GA}_{3}$ reduced the ethylene induced expression of early carotenoid biosynthetic genes and the accumulation of phytoene in orange.

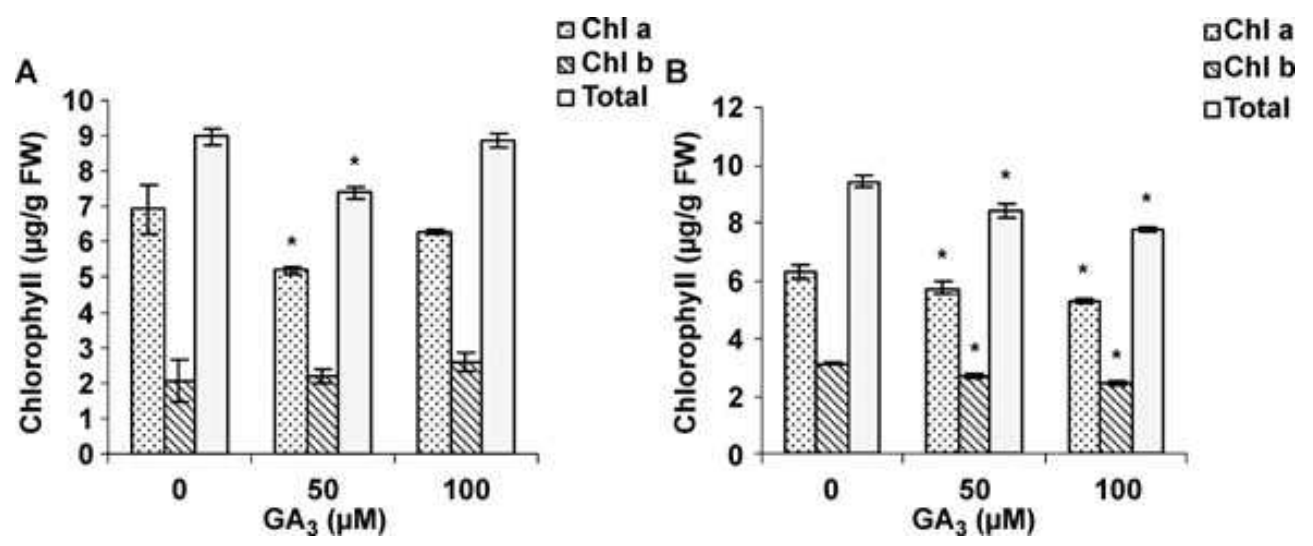

Values are means of four replications \pm standard deviation $(S D)$.

Fig. 14. Effects of gibberellic acid (GA3) on chlorophyll $a, b$ and total in leaves of male (A) and female (B) cannabis plants.

Fig. 15B shows the effect of different concentrations of $\mathrm{GA}_{3}$ on a - tocopherol content all concentrations of $\mathrm{GA}_{3}$ sprayed on leaves caused an increase in $a-$ tocopherol content in both sexes. The highest increase was detected with $50 u \mathrm{M} \mathrm{GA}_{3}$ in male plants. Apparently, 
the pattern of changes in a - tocopherol content was an invert of that in chlorophyll and carotenoid contents.

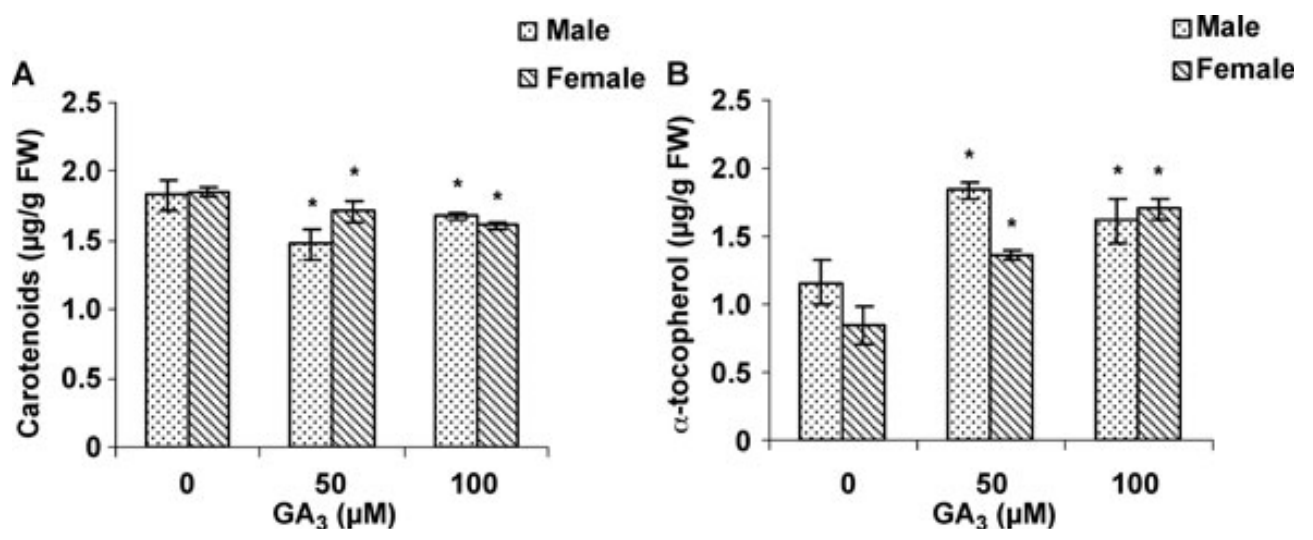

Values are means of four replications \pm standard deviation $(S D)$.

Fig. 15. Effects of gibberellic acid (GA3) on (A) carotenoids and (B) $a$-tocopherol in leaves of female and male cannabis plants.

Tocopherols ( $a, \beta, \gamma$, and $\delta$ - tocopherol) are lipophilic antioxidants that collectively constitute vitamin E (Crowell et al, 2008). Therefore, we measured the changes in the amounts of a - tocopherol in response to $\mathrm{GA}_{3}$ treatment. Our results showed that $\mathrm{GA}_{3}$ increased $a-$ tocopherol content in cannabis plants (Mansouri et al., 2009). A stimulatory effect of applied $\mathrm{GA}_{3}$ on a - tocopherol content was also absorbed in Catharanthus roseus (Abdul Jaleel et al., 2007). On the other hand, we found a reversed relationship between photosynthetic pigments (chlorophyll and carotenoids) and a- tocopherol contents in treated plants with $\mathrm{GA}_{3}$. Both $a-$ tocopherol and chlorophyll contain a phytol moiety as part of their molecule. The substrate used for their biosynthesis may be derived from a common pool. It is possible that the decrease in chlorophyll and carotenoid biosynthesis caused an increase in the substrate accumulation and therefore biosynthesis. Also Rise et al. (1989) reported a transient increase in a- tocopherol accompanied with a decrease in chlorophyll during the course of senescence in several plant species. Their results indicated that the phytol released by chlorophylase during the initial stages of chlorophyll breakdown, perhaps used for the biosynthesis of $a-$ tocopherol during senescence.

The effects of $\mathrm{GA}_{3}$ on key enzyme activity of terpenoid biosynthetic pathways (DXS and HMGR) were investigated. As shown in Fig. 16 male plants had more DXS activity than female plants and a significant decrease was observed over DXS activity in treated plants (male and female) by $\mathrm{GA}_{3}$ which was liner with increasing $\mathrm{GA}_{3}$ concentration. $\mathrm{GA}_{3}$ treatment had a stronger effect on decreasing DXS activity in male plants.

$\mathrm{GA}_{3}$ treatment caused a decrease in the 1-deoxy-D-xylulose5-phosphate synthase (DXS) activity in male and female of Cannabis sativa plants (Mansouri et al., 2009).This is the first report about the effect of $\mathrm{GA}_{3}$ on DXS activity. Many reports support a regulatory role of DXS for the production of MEP- derived isoprenoids in plants (Rodriguez-Concepcion 2006). Estevez et al. (2001) reported that transgene-mediated up regulation or down 
regulation of DXS levels in Arabidopsis were correlated with concomitant changes in the levels of MEP-derived isoprenoid end products. However, in our investigation, the decrease in the entire MEP pathway end product. The results showed an increase in a-tocopherol content and a decrease in chlorophyll and carotenids. These data support this hypothesis that several enzymes share control over the metabolic flux through the MEP pathway. The MEP pathway might be regulated at several control points to compensate for fluctuations in precursor/product equilibrium and redistribute the balance of control within the pathway (Enfissi et al., 2005). Another possibility for this uncoordinated activity between the DXS and the plastidic isoprenoids is the exchange or precursors between the cytosol and the plastid. Strong biochemical evidence for such exchange of precursors was reported by Kasahara et al., (2002), Nagata et al. (2002) and Hemmerlin et al. (2003).
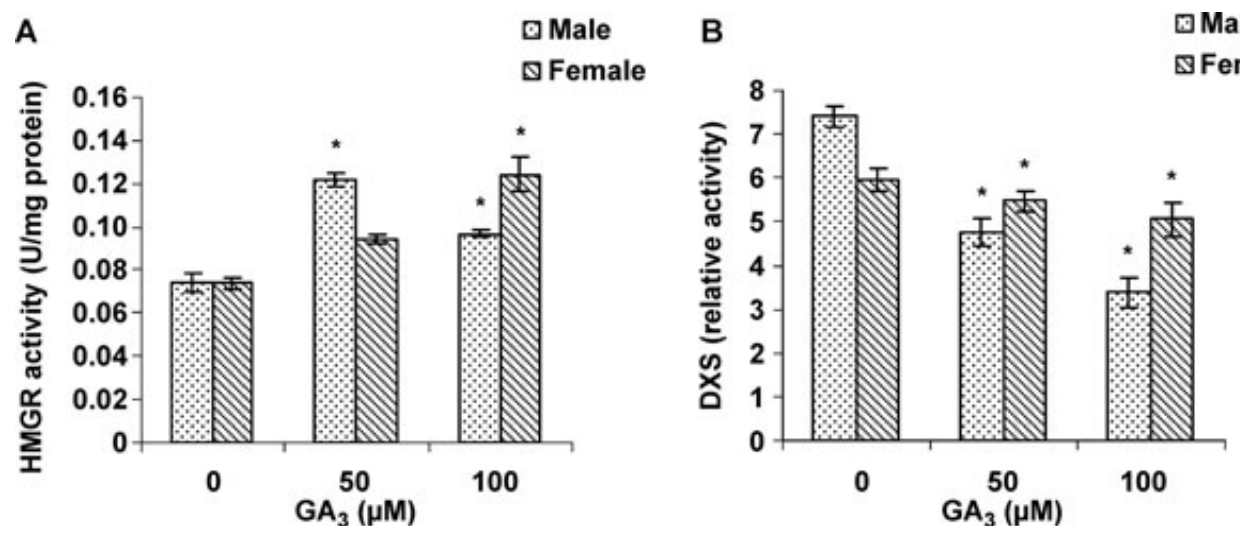

(HMGR) activities in the leaves of female and male cannabis plants. Values are means of four replications \pm standard deviation $(S D)$.

Fig. 16. Effects of gibberellic acid (GA3) on 1-deoxy-D-xylulose 5-phosphate synthase (DXS) and 3-hydroxy-3-methylglutaryl coenzyme A reductase.

Gibberellic acid treatment increased HMGR activity in the treated plants (Fig. 16). However some differences are obvious between the two groups of plants of different sexes (Fig.16). The male individuals had a greater HMGR activity at lower $\mathrm{GA}_{3}$ concentrations than female plants.

Activity of 3-hydroxy-3-methyglutaryl coenzyme A reductase (HMGR) in cannabis plants demonstrated that HMGR activity was greater in plants treated with GA3. Consistent with our result, Russell and Davidson (1982) reported that GA3 increased HMGR activity in pea seedlings. It was shown that higher levels of HMGR activity were usually associated with rapidly growing parts of plants (Brooker and Russell 1975). On the othe words, Ga is widely regarded as a growth-promoting compound. Thus, it can be a candidate for stimulating of the HMGR activity. The lower HMGR activity was seen in the male plants treated with 100 $\mu \mathrm{M} \mathrm{GA}_{3}$. The decrease observed in the HMGR activity could reflect the $\mathrm{GA}_{3}$ interaction in high concentration with other plant hormones. As it has been shown that exogenous application of $\mathrm{GA}_{3}$ caused a clear increase in ACC content, ACC oxidase activity and ethylene biosynthesis occur during the breaking of dormancy and onset of germination in Fagus sylvatica seeds (Calvo et al. 2004). In addition, it is possible that ethylene caused the decrease observed in HMGR activity. 
The mature leaves of male and female cannabis plants were used to determine the effect of GA3 on squalene (biosynthetic precursor to all steroids), campestrol, stigmasterol, and sitosterol (the most representative phytosteroids of the MVA pathway). A significant increase in squalene (Fig. 17), stigmasterol and sitosterol accumulation occurred in female and male plants treated with gibberellic acid (Fig. 18). The changes in the amount of squalene and sitosterol were coordinate with the changes in HMGR activity. In addition, GA3 had a stimulatory effect on campestrol accumulation in male plants.

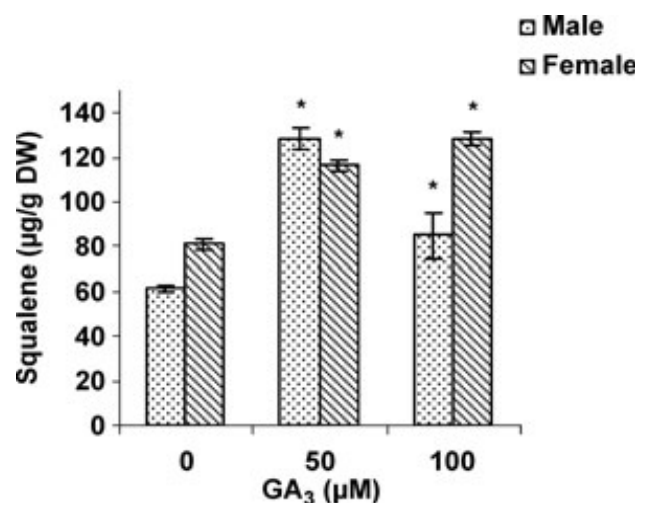

(HMGR) activities in the leaves of female and male cannabis plants. Values are means of four replications \pm standard deviation $(S D)$.

Fig. 17. Effects of gibberellic acid (GA3) on squalene content in leaves of female and male cannabis plants.

The data in our study showed that $\mathrm{GA}_{3}$ treatment increased squalene and phytostrol contents in a pattern similar to the changes in the HMGR acitivity. Since HMGR is an important control point for the MVA pathway in plants (Kato-Emori et al. 2001), the increase in HMGR activity should result in increasing the supply of phytostrols. Free sterols are found predominantly in cell membranes and are thought to contribute to the proper functioning of membranes by controlling the fluidity characteristics of the membrane (Devarenne et al. 2002). Douglas and paleg (1974) demonstrated that the inhibitors of GAs biosynthesis caused a decrease in sterol accumulation. Huttly and Philips (1995) suggested that $\mathrm{GA}_{3}$ causes an increase in cell number and size to produce a significant effect. Since these processes need the production of cell membrane. It can be assumed that $\mathrm{GA}_{3}$ should induce the phytostrol biosynthesis to influence its effects on growth in plants.

A comparison between male and female plants showed that females had higher amounts of THC; especially in the flowers (Fig. 19). THC content of the leaves was slightly lower than that of flowers. The application of $\mathrm{GA}_{3}$ to cannabis plants resulted in a decrease in THC content. Gibberellic acid treatment had a stronger effect in decreasing THC content in the flowers of male plants in comparison with that of female plants. However, the leaves of the two sexes indicated similar responses to $\mathrm{GA}_{3}$ treatment.

$\Delta^{9}$-tetrahydrocannabinol (THC) is the cannabinoid responsible for the main psychoactive effects of most Cannabis drug preparations (Mecoulam 1970). Factors that control 
biosynthesis and distribution of cannabinoids within the plant are unknown. We investigated the impact of altered GA3 levels on this secondary metabolite in C.sativa, and the results indicated that apart from the influence of GA3, female plants had more THC than male plants in leaves and flowers. The treated plants with GA3 had lower THC content in comparison with that in control plants. It is demonstrated that cannabinoids are synthesized from the DXP pathway (Fellemeier et al. 2001). Furthermore, our results showed that GA3 decreased THC content by decreasing the DXS activity and necessary precursors for THC biosynthesis.

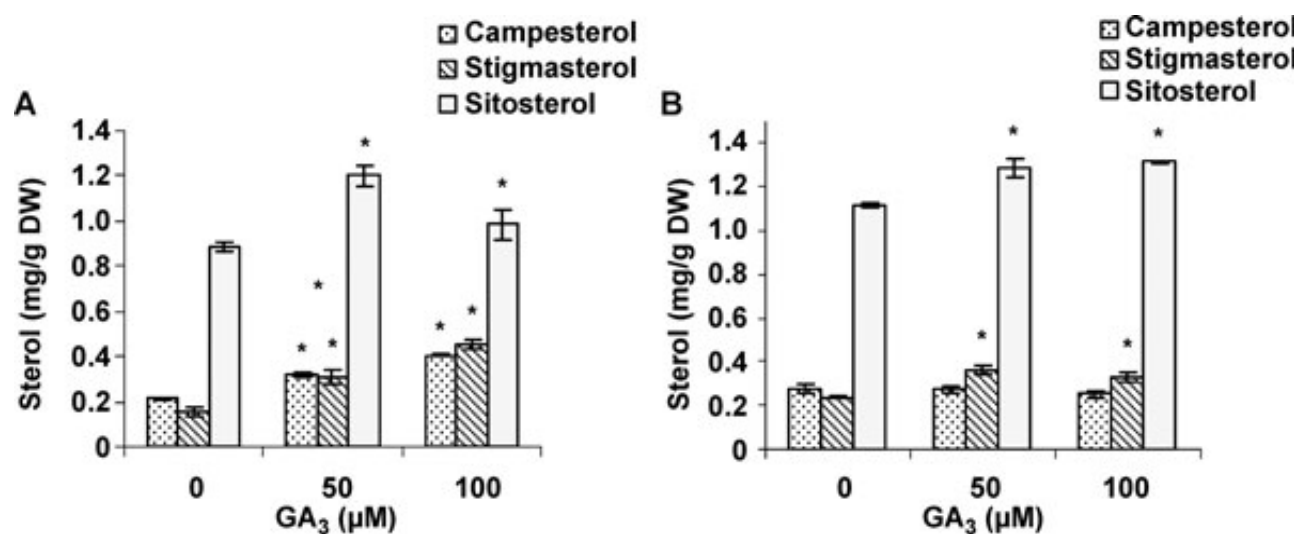

(HMGR) activities in the leaves of female and male cannabis plants.

Values are means of four replications \pm standard deviation $(S D)$.

Fig. 18. Effects of gibberellic acid (GA3) on campesterol, stigmasterol and sitosterol content in leaves of (A) male and (B) female cannabis plants.

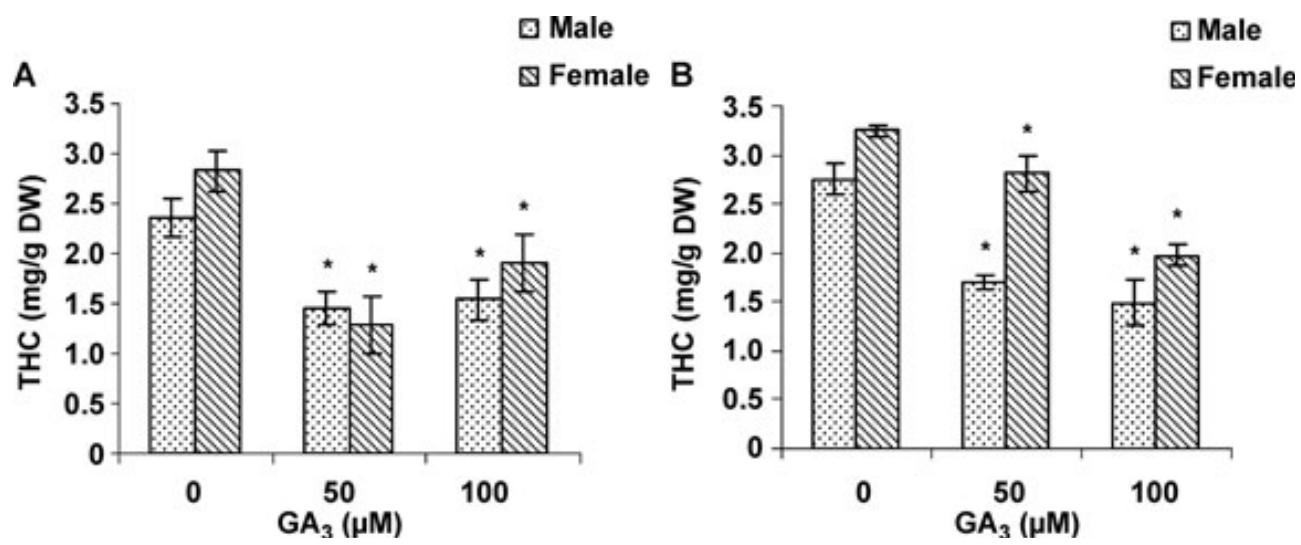

(HMGR) activities in the leaves of female and male cannabis plants.

Values are means of four replications \pm standard deviation $(S D)$.

Fig. 19. Effect of gibberellic acid (GA3) on_9-tetrahydrocannabinol (THC) content in (A) leaves and (B) flowers of the male and female cannabis plants. 


\section{Conclusion}

In conclusion, the pattern of changes in the amounts of primary terpenoids (chlorophyll, carotenoids, and phytosterols) in Cannabis sativa suggest that GA3 have opposite effects on the primary terpenoid biosynthesis of MEP and MVA pathways. In addition, the appearance of the direct relationship between DXS and HMGR activity, and their main end products confirm an important role for these enzymes in the MEP and MVA pathways regulation. However, to understand the role of GA3 in terpenoid biosynthesis regulation, we need further investigation.

\section{Acknowledgement}

The autor wishes to thank Mr. Hossein Mozafari phD student of Shahid Bahonar university of Kerman for his critical comments and help of the manuscript.

\section{References}

Aach, H.; Bode, H.; Robinson, DG. \& Graebe, JE. (1997). ent-Kaurene synthase is located in proplastids of meristematic shoot tissues, Planta, Vol.202, pp.211-219.

Aach, H.; Bose, G. \& Graebe, JE. (1995).ent-Kaurene biosynthesis in a cell-free system from wheat (Triticum aestivum 1.) seedlings and the localization of ent-Kaurene synthase in plastids of three species, Planta, Vol.197, pp. 333-342

Abdul Jaleel, c.; Gopi, R.; Manivannan, P.; Sankar, B.; Kishorekumar, A. \& Panneerselvam, R. (2007). Antioxidant potentials and ajmalicine accumulation in Catharanthus roseus after treatment with gibberellic acid. Colloids Surf B Biointerf. Vol. 60, pp.195-200.

Agurell, S. \& Nilsson, LG. (1972). The chemistry and biological activity of cannabis. Bullet. Narcotic. pp 35-37.

Arigoni, D.; Sagner, S.; Latzel, C.; Eisenrich, W.; Bacher , A. \& Zenk, MH. (1997). Terpenoidbiosynthesis from 1-deoxy-D-xylulose in higher plants by intermolecular skeletal rearrangement, Proc Natl Acad Sci, Vol. 94, pp.10600-10605.

Bora, RK. \& Sarma, CM. (2006). Effect of gibberellic acid and Cycoel on growth, yield and protein content of pea. Asi J plant Sci. Vol.5, pp.324-330.

Brooker, JD. Russell, DW. (1975). Properties of microsomal 3-hydroxy-3-methylglutaryl coenzyme A reductase from Pisum sativum seedings, Arch. Biochem. Biophys. Vol. 167, pp723-729

Calvo, Ap.; Nicolas, C.; Lorenzo, O.; Nicolas, G. \& Rodriguez, D. (2004). Evidence for positive regulation by gibberellins and ethylene of ACC oxidase expression and activity during transition from dormancy to germination in Fagus sylvatica L. seeds,J. Plant Growth Regul. Vol. 23, pp.44-53.

Crowell, EF., McGrath, JM.\& Douches, DS,. (2008). Accomulation of vitamin E in potato (Solanum toberosum) tubers, Transgenic Res. Vol.17, pp.205-217.

Crowell, EF.; Mcgrath, Jm.\& Douches, DS. (2008). Accumulation of vitE in potato ( Salanum tuberosum) tubers, Transgenic Res. Vol. 17 pp.205-217.

Crozier, A.; Kamiya, Y.; Bishop, G. \& Yokota, T. (2000). Biosynthesis of hormones and elicitor molecules. In: Buchanan BB, Gruissem W, Jones RL (eds) Biochemistry and molecular biology of plants, Amer Soc Plant Physio, Roclville, pp.850-929. 
Devarenne, TP.; Ghosh, A. \& Chappell, J. (2002). Regulation of squalene synthase, a key enzyme of sterol biosynthesis, in tobacco. Plant Physiol. Vol 129, pp 181-222.

Dewick, PM. (2002). The biosynthesis of C5-C25 terpenoid compounds, Nat Prod Rep, Vol.19, pp.181-222.

Dogbo O. \& Camara, B. (1987). Purification of isopentenyl pyrophosphate isomerase and geranylgeranyl pyrophosphate synthase from Capsicum chrooplasts by affinity chromatography. Biochim Biophys Acta. Vol. 920, pp.140-148.

Douglas, TG.; Paleg, LG. (1974). Plant Physiol. Vol 54, pp 238-245.

Eisenreich, W.; Rojdich, F. \& Bacher, A. (2001). Deoxyxylulose phosphate pathway to terpenoids, Trends Plant Sci., Vol.6, pp.78-84.

Enfissi, MA.; Fraser, PD.; Lois, LM.; Boronat, A.; Schuch, W. \& Bramley, PM. (2005). Metabolic engineering of the mevalonate and non-mevalonate isopentenyl diphosphate-forming pathways for the production of health-promoting isoprenoids in tomato, Plant Biotech J, Vol.3, pp.17-27.

Estevez, JM.; Cantero, A.; Reindl, A.; Reichler, S. \& Leon, P. (2001) 1-deoxy-D-Xylulose 5phosphate synthase, limiting enzyme for plastidic isoprenoid biosynthesis in plants, J Bio Chem Vol. 276, pp. 22901-22909.

Fellermeier, M.; Eisenreich,W.; Bacher, A. \& Zenk, MH. (2001). Biosynthesis of cannabinoids: incorporation experiment with 13C-labeled glucoses, Eur. J. Biochem. Vol. 268, pp1596-1604.

Fellermeier, M.; Eisereich, W.; Bacher, A. \& Zenk, MH. (2001). Biosynthsis of cannabinoids: incorporation experiments with 13C- labeled glucose. Eur J Biochem Vol.268, pp.1596-1604.

Goldschmidt, EE. (1988). Regulatory aspects of chloro-chromoplast interconversion in seeding citrus fruit peel, Isr. J. Bot. Vol. 37, pp.23-130.

Gusman, M. (2003). Cannabinoids: potential anticancer agents, Nat. Rev. Vol. 3, pp. 745-755.

Hedden, P. \& Kamiya, Y. (1997). Gibberellin biosynthesis enzymes, genes and their regulation, AnnRev Plant Physiol Plant Mol Biol, Vol.48, pp.431-460.

Heldt, HW., (2005). A large diversity of isoprenoids has multiple functions in plant metabolism, Plant Biochemistry. $3^{\text {rd }}$ Edition ISBN: 0-12-088391-0

Hemmerlin, A.; Hoeffler, JF.; Meyer, O.; Tritsch, D.; Kagan, IA. \& Grosdemanage-Billiard C. (2003). Cross talk between the cytosolic mevalonate and the plastidial methlerythritol phosphate pathways in tobacco Bright Yellow-2 cells, J. BIol. Chem. Vol.278, pp.26666-26676

Hilling, KW. (2004). A chemotaxonomic analysis of terpenoid variation in cannabis, Biochem. Systems Ecol. Vol. 32, pp. 875-891

Hischberg, J. (1999). Production of high value compounds: carotenoids and vitamin E, Curr. Opin. Biotechnol, Vol. 20, pp.186-191.

Howlett, AC.; Breivogel, CS.; Cholders, SR.; Deadwyler, SA. Hampson, Re. \& Porrino LY (2004). d physiology and pharmacology: 30 year progress. Neuropharmacol. Vol. 47, pp. 345-358.

Huttly, AK. \& Phillips, AL. (1995). Gibberellin regulated plant genes. Physol. Plant. Vol. 95, pp. 310-317.

Kanno, Y.; Otomo, K.; Kenmoku, H.; Mitsuhashi, W.; Yamane, H.; Oikawa, H.; Toshima, H.; Matsuoka, M.; Sassa, T. \& Toyomasu, T. (2006). Characterization of a rice gene 
family encoding type A diterpene cyclases, Biosci Biotechnol Biochem, Vol. 70, pp.1702-1710.

Kasahara, H, Hanada A, Kuzuyama T, Takagi M, Kamiya Y, Yamaguchi S. (2002).Contribution of the mevalonate and methylerythritol phosphate pathways to the biosynthesis of gibberellin in Arabidopsis, J. Biol. Chem. Vol. 277, pp. 4518845194.

Kato-Emori, S, Higashi K, Hosoga K, Kobayashi T, Ezura H (2001). Cloning and characterizing of the gene encoding 3-hydroxy-3-methylglutaryl coenzyme A reductase in melon (Cucumic melo L. reticulatus), Mol. Genet. Genomics Vol. 265, pp. 135-142.

Lang, Bm. \& Ghassemian, M. (2003). Genome organization in Arabidopsis thaliana : a survey for gene involved in isoprenoid and chlorophyll metabolism. Plant Mol Biol, vol. 51 pp. 925-948.

Lang, H. (1998). Molecular biology of gibberelline synthesis, Plant, Vol.204 pp. 409-419.

Lang, T. \& Graebe, JE. (1993). Enzymes of gibberellins synthesis. In: Lea PJ (ed) Method in plant biochemistry, Vol.9, Academic Press, London, pp.403-430.

Lange, BM. \& Croteau, R. (1999). Genetic engineering of essential oil production in mint, Curr Opin Pant Biol, Vol.2, pp.139-144.

Laule, O.; Futholz, A.; Chang, HS.; Zhu, T.; Wang, X. \& Heifetz, PB. (2003). Cross talk between cytosolic and plastidial pathways of isoprenoid biosynthesis inArabidopsis thaliana, Plant Biol, Vol.100, pp.6866-6871.

Lichtenthaler, HK. (1999). The 1-deoxy-D-xylulose-5-phosphate pathway of isoprenoid biosynthesis in plants. Annual Review of plant physiology and plant molecular biology, Vol. 50, pp.47-65.

Lichtenthaler, HK.; Rohmer, M. \& Schwender, J. (1997) Two independent biochemical pathways for isopentenyl diphosphate and isoprenoid biosynthesis in higher plants. Pysiol plant, vol. 101 pp. 643-652.

MaGarvey, DJ. \& Croteau, R. (1995). Terpenoid metabolism. The plant cells Vol. 7, pp. 10151026.

Mansouri, H.; Asrar, Z. \& Amarowicz, R. (2011). The respose of terpenoids to exogenous gibberellic acid in Cannabis sativa at vegetative stage, Acta physiol plant, Vol.33, pp.1085-1091.

Mansouri, H.; Asrar, Z. \& Mehrabani, M. (2009) Effect of gibberellic acid on primary terpenoids and Tetrahydrocannabinol in Cannabis sativa at flowerin stage. Journal of integrative plant Biology Vol. 51, pp. 553-561.

McCaskill, D. \& Croteau, R. (1998). Some caveats for bioengineering terpenoid metabolism in plants, TIBITECH, Vol.16, pp.349-355.

Mechoulam, R. (1970). Marijuana chemistry. Science, Vol. 168, pp.1159-1166.

Misra, AN. Biswal, UC. (1980). Effect of photohormons on chlorophyll degradation during again of chloroplasts in vivo and in vitro, Protoplasma Vol. 105, pp. 1-8.

Monge, E.; Aguirre. R. \& Blanco, A. (1994). Application of paclobutrazol and $\mathrm{GA}_{3}$ to adult peach trees: effects on nutritional status and photosynthetic pigments, J. Plant Growth Regul. Vol. 13, pp. 15-19.

Negata, N.; Suzuki, M.; Yoshida, S. \& Muranaka, T. (2002). Mevalonic acid partially restres chloroplast and etioplast development in Arabidopsis lacing the non-mevalonate pathway, Planta, Vol.216, pp.345-350 
Olszewski, N.; Sun, T. \& Gubler, T. (2002). Gibberellin signaling: Biosynthesis, catabolism, and response pathways, Plan Cell, Vol.14, pp.61-80.

Perez, AT.; Marsh, HV. \& Lachman, WH. (1974). Physiology of the the yellow -green 6 gene in tomato, Plant Physiol, Vol.53, pp.192-197.

Pfander, H. (1992). Carotenoids: an overview, Meth Enzymol, Vol.213, pp.3-13.

Razem, FA.; Baron, K. \& Hill, RD. (2006). Turning on gibberellins and abscisic acid signaling, Curr Opin Plant Bio, Vol.9, pp.454-459.

Rise, M.; Conjocaru, M.; Gottlieb, HE. \& Goldschmidt, EE. (1989). Accumulation of tocopherol in sensscing organs as related to chlorophyll degradation, Plant Physiol, Vol.89, pp.1028-1030.

Rodrigo, MJ. \& Zacarias, L. (2007). Effect of postharvested ethylene treatment on carotenoid accumulation and the expression of carotenoid biosynthetic genes in the flavedo of orange (Citrus sinensis L.), Postharvest Biol Technol, Vol.43, pp.14-22.

Rodriguez-concecion, M. (2006). Early steps in isoprenoid biosynthesis: Multilevel regulation of the supply of common precursors in plant cells, Phytochem Rev, Vol.5, pp.1-15.

Rodriguez-concepcion, M. \& Boronat, A. (2002). Elucidation of the methylerythritol phosphate pathwayfor isoprenoids biosynthesis in bacteria and plastids, A metabolic milestone achieved through genomics, Plant Physiol, Vol. 130, pp.10791089.

Russell, DW. \& Davidson, H. (1982). Regulationof cytosolic HMG-CoA reductase activity in pea seedlings: contrasting responses to different hormones, and hormone product interaction, suggest hormonal modulation of activity, Biochem. Biophys. Res. Commun. Vol. 104pp. 1537-1543.

Shinjiro, Y. (2008). Gibberellin Metaboilism and its regulation, Anne. Rev. plant Biol. Vol. 59, pp. 225-251.

Shintani, D. \& Della Penna, D. (1998). Elevation the Vit E content of plants through metabolic engineering, Science, Vol.282, pp.2098-2100.

Szymanska, R. \& Kruk, J. (2008). a-tocopherol content and isomers composition in selected plant species, Plant Physiol Biochem, Vol.46, pp.29-33.

Yabuta, T. (1935). Biochemistry of the "Bakabae'fungus of rice". Agr. Hort. Vol. 10, pp. 17-22.

Yim, KD.; Kwon, YW. \& Bayer, DE. (1997). Growth response and allocation of assimilates of rice seedlings by paclobutrazol and gibberellins treatment, J Plant Growth Regul, Vol.16, pp.35-41. 


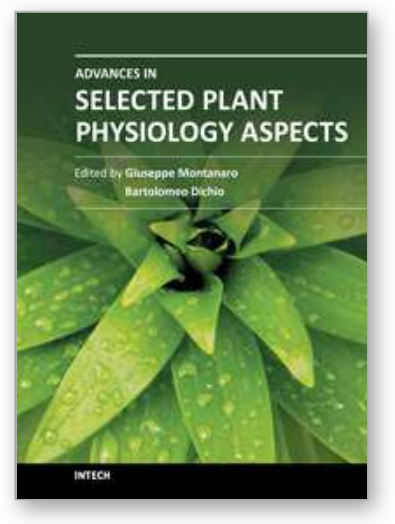

\author{
Advances in Selected Plant Physiology Aspects \\ Edited by Dr. Giuseppe Montanaro
}

ISBN 978-953-51-0557-2

Hard cover, 388 pages

Publisher InTech

Published online 25, April, 2012

Published in print edition April, 2012

The book provides general principles and new insights of some plant physiology aspects covering abiotic stress, plant water relations, mineral nutrition and reproduction. Plant response to reduced water availability and other abiotic stress (e.g. metals) have been analysed through changes in water absorption and transport mechanisms, as well as by molecular and genetic approach. A relatively new aspects of fruit nutrition are presented in order to provide the basis for the improvement of some fruit quality traits. The involvement of hormones, nutritional and proteomic plant profiles together with some structure/function of sexual components have also been addressed. Written by leading scientists from around the world it may serve as source of methods, theories, ideas and tools for students, researchers and experts in that areas of plant physiology.

\title{
How to reference
}

In order to correctly reference this scholarly work, feel free to copy and paste the following:

Zahra Asrar (2012). Terpenoids and Gibberellic Acids Interaction in Plants, Advances in Selected Plant Physiology Aspects, Dr. Giuseppe Montanaro (Ed.), ISBN: 978-953-51-0557-2, InTech, Available from: http://www.intechopen.com/books/advances-in-selected-plant-physiology-aspects/the-interaction-effect-ofsome-terpenoids-and-gibberellic-acid-in-cannabis-sativa-at-vegetative

\section{INTECH}

open science | open minds

\section{InTech Europe}

University Campus STeP Ri

Slavka Krautzeka 83/A

51000 Rijeka, Croatia

Phone: +385 (51) 770447

Fax: +385 (51) 686166

www.intechopen.com

\section{InTech China}

Unit 405, Office Block, Hotel Equatorial Shanghai

No.65, Yan An Road (West), Shanghai, 200040, China

中国上海市延安西路65号上海国际贵都大饭店办公楼405单元

Phone: +86-21-62489820

Fax: +86-21-62489821 
(C) 2012 The Author(s). Licensee IntechOpen. This is an open access article distributed under the terms of the Creative Commons Attribution 3.0 License, which permits unrestricted use, distribution, and reproduction in any medium, provided the original work is properly cited. 